\title{
ENTRE LA PATRIMONIALIZACIÓN Y LA INVENCIÓN DE LA TRADICIÓN: LAS IGLESIAS DE PETORCA, 1775-1910
}

\author{
BETWEEN HERITAGE AND THE INVENTION OF TRADITION: \\ THE CHURCHES OF PETORCA 1775-1910
}

\author{
Milton Godoy Orellana*
}

"La novedad no es menos novel por poder vestir con facilidad el ropaje de la antigüedad". Eric Hobsbawm, La invención de la tradición, 1992.

\author{
"Hay lugares de memoria \\ porque ya no hay ámbitos de memoria" \\ Pierre Nora, Les lieux de mémoire, 1984.
}

\begin{abstract}
El artículo analiza el proceso de patrimonialización y las falacias que, en ocasiones, se instalan para recrear elementos patrimoniales perdidos o que después de exponerse a sucesivas transformaciones hacen que sus modificaciones les conviertan en una construcción diferente al inmueble que se pretende declarar como patrimonial. Para el efecto, se analiza el concepto de patrimonio y su declaración como tal a partir de la iglesia de Petorca. La investigación se basa en las diferentes iglesias construidas en el mismo sitio y su destrucción por terremotos hasta establecer la construcción actual, a la que se le asigna un pasado que no le corresponde, en una verdadera invención de una tradición local.
\end{abstract}

Palabras claves: Patrimonio, iglesia de Petorca, monumento nacional.

The paper analyzes the process of canonization and fallacies that sometimes installed to recreate lost assets or after exposure to successive transformations make amendments will become a different property that is intended to be declared as heritage building. To this end, the concept of heritage and its declaration as such from the church Petorca discussed. For this purpose, different churches built on the same site and its destruction by earthquakes to set the current building, which is assigned a past that does not belong in a true invention of a local tradition are analyzed.

Key words: Heritage, Church Petorca, National Monument.

\section{Introducción}

Desde hace algunas décadas, en Chile los procesos de declaración de monumentos nacionales de construcciones privadas, estatales y eclesiásticas han tendido a aumentar en aras de la salvaguardia patrimonial, la restauración y la valorización de estos inmuebles, donde los impulsores de dichos procesos están movidos por variados intereses -no exentos de móviles políticos y económicos-, entre los que se cuenta el afán de protección del escaso patrimonio arquitectónico existente en el país. No obstante, este proceso ha traído consigo una serie de falacias que buscan recrear elementos patrimoniales perdidos o cuyas sucesivas transformaciones dan pie para comprender que definitivamente se está frente a otra construcción y que del pasado arquitectónico del inmueble solo quedan sus cimientos $\mathrm{y}$, en ocasiones, ni siquiera aquellos, como ocurre en el caso del inmueble eclesiástico que motiva este trabajo. Más allá del cuestionamiento acerca de qué, quién y por qué se declara elemento patrimonial uno y no otro inmueble, cabe preguntarse: ¿cuál es la idea e intención que subyace en estas patrimonializaciones forzadas? Las que en múltiples ocasiones están sustentadas en falacias refrendadas académicamente por investigaciones destinadas a generar un expediente técnico que permita solicitar la condición de elemento patrimonial frente a la decisión de especialistas aunados en el Consejo de Monumentos Nacionales. Así, el tenor de las justificaciones presentadas en el caso de la iglesia

* Universidad Arturo Prat, Instituto de Estudios Internacionales (INTE). Universidad Academia de Humanismo Cristiano, Santiago. Correo electrónico: mgodoyorellana@gmail.cl 
en discusión establece que "en el pasado como en la actualidad constituye un símbolo representativo no solo arquitectónico de esta zona minero-agrícola, sino también de la identidad cultural petorquina. Es esta cualidad que le da unidad al conjunto de construcciones y reconstrucciones que ha tenido desde comienzos del siglo XVII hasta comienzos del siglo XX" (Hernández, 2008). ¿No es este el caso de todas las iglesias cuya reconstrucción se realizó en el mismo sitio en una determinada ciudad desde illo tempore? ¿Cuál es la idea de apelar a una antigüedad que la documentación no reconoce?

Sabido es que la noción de patrimonio urbano histórico unida a un proyecto de conservación aparece en la Europa de segunda mitad del siglo XIX, en la época del barón Haussman, en Francia, y John Ruskin, en Inglaterra, reconociéndose en este concepto un difícil desarrollo (Choay, 2007). De hecho, en la actualidad la condición de patrimonio conlleva el proceso de patrimonialización, resultado según Llorenç Prats de dos construcciones sociales que se complementan, a saber, la sacralización de la externalidad cultural en que se sustenta el patrimonio constituido por reliquias, entre las que se considera el "pasado (como tiempo fuera del tiempo, por oposición, no al tiempo presente, sino al tiempo percibido como presente)". En segundo lugar, el modelo de Prats apela a la puesta en valor, que considera la valoración y la activación, instancia en que el patrimonio depende exclusivamente del poder político (Prats, 2005).

Este concepto de patrimonialización ligada al ejercicio del poder se relaciona de manera práctica a la idea desarrollada por Eric Hobsbawm con relación al concepto de tradición inventada, que se usa en sentido amplio, más no impreciso, y define un conjunto de prácticas destinadas a "inculcar determinados valores o normas de comportamiento, por medio de la repetición, lo que implica automáticamente continuidad con el pasado" (Hobsbawm y Ranger, 2002) y que buscan conectarse con un pasado histórico apropiado. No obstante, indica el citado historiador, la continuidad con el pasado es en gran en parte ficticia.

A propósito de la investigación desarrollada en torno a la iglesia de Petorca, su historia y la consecuente declaración como Monumento Nacional Histórico es posible constatar la existencia de este fenómeno. Pareciera que el primer elemento de esta idea es establecer estatutos de antigüedad de un determinado edificio, buscando atar con el pasado el origen de determinada ciudad o poblado, que al contar con un Monumento Nacional asegura la llegada de turistas al lugar, además de dotar de cierta prosapia temporal al vecindario, generando un hito arquitectónico. Un lugar, que en una suerte de punto axial temporal, lo engarza con su pasado. Es más, en su dimensión política estos actos no son más que los intentos desde el Estado nacional por destacar valores y símbolos hegemónicos de las elites, la iglesia y el Estado, resaltando estos y dejando en la bruma otros, principalmente aquellos de los sectores populares cuyo patrimonio cultural queda en el campo de lo intangible (Bonfil, 2005; Godoy, 2007; Morel, 2008).

La investigación que originó el presente artículo se inscribió precisamente en el proceso de restauración del mencionado monumento ${ }^{1}$, obteniendo resultados a contrapelo de lo esperado. En términos documentales, la investigación se centró en prospectar el Archivo Histórico Nacional en los fondos correspondientes a Capitanía General, Ministerio del Interior, Gobernación y Municipalidad de Petorca, además del Archivo Parroquial de Petorca. El objetivo central fue identificar y transcribir documentación que eventualmente contuviera información acerca de la historia de la iglesia de Petorca y las construcciones que le antecedieron, en el emplazamiento fijado en el periodo colonial, que mantuvo en el periodo republicano.

La información contenida en la documentación oficial es de importante valor, debido a la dependencia institucional que la Iglesia católica tenía del Estado en virtud del Patronato que, entre otros, implicaba el aporte monetario para financiar la construcción y reparación de iglesias, dejando esta relación de dependencia una importante información acerca del gasto en la iglesia local. La visión oficial se manifiesta en la correspondencia que los curas locales mantenían con la jerarquía de la Iglesia católica, la que se encuentra depositada en el Archivo del Arzobispado de Santiago. Estas fuentes se complementan con los Libros de Fábrica que consignan las entradas y salidas de dinero que mantiene la parroquia durante las diferentes administraciones. El proceso estudiado es posible analizarlo de la perspectiva asentada en los periódicos locales y en la opinión de viajeros como Head o Domeyko, quienes visitaron el poblado.

En función de esta información se pueden establecer las intervenciones hechas a las iglesias desde el siglo XVIII en adelante y se pueden cruzar 
los datos obtenidos en la bibliografía. En este aspecto el texto más destacado es Apuntes para la historia de Petorca, del cura Elías Lizana, quien fue párroco de la localidad y conoció documentación histórica de alto valor, aparte de ser testigo de los cambios suscitados en la iglesia de Petorca a fines del siglo XIX e inicio del XX.

A contrapelo de la evidencia documental analizada, el decreto manado desde el Ministerio de Educación declaró a la iglesia de Petorca Monumento Nacional Histórico a base de lo señalado por el Consejo de Monumentos Nacionales, en cuya decisión primó la consideración de la "calidad e interés histórico o artístico o por su antigüedad"2. Al sustentar su decisión, obviamente basándose en el informe técnico precedente, el consejo determinó que la iglesia "corresponde a una de las iglesias más antiguas de la zona, pues fue fundada por los jesuitas en el año 1640. El edificio ha sido reconstruido en tres oportunidades datando el que, actualmente, está en pie desde el año 1857"3.

¿Cómo se llegó a establecer dichas fechas para una construcción que en los hechos data de las primeras décadas del siglo XX? En este planteamiento resultan curiosos los datos discutidos acerca de que la iglesia fue fundada en 1640 , reconstruida tres veces, para consolidarse en 1857 y persistir hasta la actualidad, en circunstancias que desde la fundación inicial de los jesuitas hasta el edificio actual lo único que comparten todos los edificios destinados a las funciones religiosas del poblado es su emplazamiento en el mismo sitio, constituyéndose en uno de los primeros lugares de la región que contaron con este servicio, tratándose de una sucesión de edificaciones diferentes que fueron construidas o reconstruidas después de cada uno de los tantos terremotos que asolaron la región.

\section{La ciudad e iglesias de Petorca}

El poblamiento del valle de Petorca es constatable desde antes de la llegada del Incanato, donde irrumpió más tarde Almagro, quien celebró la Pascua de Resurrección, según Barros Arana, en "un pueblo de indios situado en el valle de Petorca" (Barros Arana, 1884). La zona estaba circunscrita desde el inicio de la ocupación española al Partido de Quillota e integrada a la Doctrina de El Ingenio, de la que tenía dependencia política y eclesiástica, careciendo hasta el siglo XVIII de un centro poblacional en el valle con presencia de autoridades y diseñado acorde con la legislación de Indias (Mellafe y Salinas, 1985). Desde la temprana Colonia el control se limitaba a un sacerdote que desde 1591 visitaba esporádicamente el lugar a prestar servicios religiosos, para cuyo efecto se levantó una capilla alrededor de 1600 (Lizana 1910).

En términos de propiedad, el valle de Petorca fue entregado en 1591 al Capitán Fernando Romero Gallegos. Más tarde, en 1606, las tierras fueron transferidas al convento de los Agustinos, quienes las mantuvieron bajo su total control hasta la erección final de la villa de Petorca en 1780 (McCaa, 1983). Hacia las primeras décadas del siglo XVIII el valle había sido el foco de una importante migración de mineros que respondían a las demandas de oro del periodo. De manera similar a lo acontecido en toda la región del Norte Chico donde hubo explotaciones, la llegada de mineros trajo consigo el arribo de hombres y mujeres que venían a beneficiarse del negocio, estableciendo comercios que buscaban suplir la demanda de los trabajadores. En 1779, un poeta dejó una clara impresión del movimiento que vivía el valle y, específicamente, la localidad de Petorca:
"En cuyas cumbres habitan
Gran multitud de mineros,
Que desangran sus metales
Por vetajales diversos.
Viven en su verde falda
Muchos nobles caballeros,
Mercaderes, oficiales
Vecinos y forasteros
Que en la multitud del oro
Han cifrado su comercio"4.

Durante el periodo tardocolonial y mediando el siglo XVIII Domingo Ortiz de Rosas impulsó, sustentado en el auto dictado por la Junta de Poblaciones el 20 de septiembre de 1752, una agresiva política de fundación de villas entre las que se consideró a Santa Ana de Briviesca de Petorca, en $1754^{5}$. Aunque existió la orden de erección de la villa esta se mantuvo por casi tres décadas en la informalidad y contaba solo con un acta de fundación.

Igual que el conjunto de villas fundadas durante el periodo de Ortiz de Rosas y refundadas por O'Higgins, Petorca enfrentó problemas con los hacendados vecinos que miraban con escasas simpatías el proceso que se desencadenaba en Chile en el contexto de las transformaciones que 
implementaron los Borbones, mediante el desarrollo de una política centralizadora y de control que buscaba aumentar el orden en la población y "encuadernar a los desencuadernados", como señalan las fuentes de la época. Esto partía de la premisa que la creación de villas y ciudades traería consigo un mayor proceso civilizatorio y de modernización, por lo que se procedió persistentemente a establecer y fortalecer nuevos centros poblados, lo que implicaba la fundación de una iglesia con características arquitectónicas que le dieran mayor presencia.

El caso de Petorca no difiere sustancialmente de la realidad de las villas fundadas en virtud de la junta de poblaciones de mediados de siglo, las que en conjunto generaron fricciones con los hacendados vecinos. En La Ligua, el conflicto se suscitó con el dueño de la hacienda de Pullally, mientras que en Petorca las diferencias se dieron con los religiosos de San Agustín asentados en el valle, quienes demandaban la propiedad de las tierras en que se emplazaría la futura villa y el beneficio de los arriendos de terreno a quienes con antelación se hallaban instalados en el lugar. De esta manera, después de las fundaciones que podríamos calificar como "de papel" realizadas por Domingo Ortiz de Rosas, se provocaron extensos juicios para definir el lugar de la instalación definitiva del poblado ${ }^{6}$. La disputa se centraba en que los agustinos reclamaban sus derechos y los pagos atrasados de arriendos de sitios.

Ante la resolución del rey, los vecinos del lugar se cicuncribieron al diseño de la nueva trama urbana, aunque implicaba "echar muchas casas abajo para entrarlas en línea”, condición que aceptaban, "gustosos por contemplarnos tierra en casa propia y libertados de las imponderables extorsiones que hemos experimentado en cerca de cincuenta años que ha que se descubrió este mineral""

La propiedad de los terrenos donde se emplazarían las nuevas villas fue un aspecto central en la política de poblaciones dieciochesca, siendo un motivo que impidió durante alrededor de tres décadas establecer las poblaciones con arreglo al urbanismo indiano. Según Robert McCaa, las demandas judiciales del convento pudieron retrasar la fundación por cerca de 25 años (17531780) de pleitos destinados a "asegurarse que los sostenedores de nuevo título proporcionaran la indemnización para las tierras perdidas con un pago al contado inmediato o un censo anual" (McCaa, 1983).
Prueba de lo anterior es que recién el 17 de marzo de 1780 Antonio Martínez de Matta, abogado de la Real Audiencia, y Antonio Lozada, juez agrimensor, fueron comisionados "para el establecimiento y formación de esta población" el proceso de instalación de la villa sobre la base de lo ya establecido, realizándose la matrícula de pobladores, el repartimiento de solares y chacras "atendiendo a los actuales arriendos, y ubicaciones en que se hallan establecidos"9.

Del texto anterior se desprende que la fundación realizada en 1754 fue, más que una fundación materializada en una villa, un proyecto, debido a que esta se inició solo en 1780 y que el emplazamiento del damero característico de estas fundaciones se adecuó a los arriendos preexistentes y, en suma, que la distribución de la villa se hizo acorde con el emplazamiento de su iglesia construida en 1775. Probablemente, el alto costo, magnificencia e importancia de la edificación religiosa, a la par de la influencia del poder eclesiástico, hizo que la construcción no corriera el riesgo de ser demolida, como aconteció en La Ligua donde el zaguán y parte de la casa del cura fueron derribadas sin reclamos posteriores, porque como declaró en 1790 el cura Nicolás Olivares "todos los perjudicados con la cuerda lo llevaron con paciencia y sin hacer la menor repugnancia"10.

Por tanto, la demarcación final de la villa se hizo con arreglo a la ubicación de la iglesia preexistente, determinando la forma final del poblado con arreglo al factor geográfico que, al igual que en la mayoría de las fundaciones dieciochescas del Norte Chico, se adaptó al eje latitudinal que caracteriza al sistema orogénico andino-costero. Así se configuró una villa alargada en el sentido este-oeste, paradójicamente limitada por la presencia del río hacia el sur; y por la carencia del recurso agua hacia el norte, que sumada a la pendiente de los cerros hacía imposible se habitara en las cotas mayores ${ }^{11}$.

En efecto, la importancia de Petorca fue mayúscula, ya que hacia 1813 la villa contaba con 2.836 habitantes y 21 trapiches en funcionamiento, proveídos de mineral por 12 estacas, minas en explotación en los sectores aledaños (Egaña, 1954), y aunque poseía una docena de haciendas y predios, su expansión estaba ligada a la situación de la minería, cuyos reveses hacían que la villa presentara grandes dificultades económicas y sociales. Desde 1840 y hasta la década de los ochenta la población tendió a crecer, para iniciar su caída debido al impacto de 
la crisis económica de los setenta (Ortega, 2005) y el colapso de la minería del cobre a fines del siglo XIX. La recuperación solo se produjo -no exenta de vaivenes- desde 1907 en adelante por efecto de los movimientos hacia y desde las tierras salitreras. Desde allí en adelante la población sufrió un importante descenso, a menos de la mitad de sus habitantes en 1930, para estabilizarse hasta 1970 en un promedio de 8.000 habitantes.

El complejo proceso de movimiento de población durante el inicio del siglo XX fue influido por el éxodo del campo a la ciudad y por efecto del desplazamiento desde pueblos interiores a ciudades menores e intermedias, produciendo el despoblamiento de antiguos villorrios que habían concentrado una importante masa de población e iniciaban un proceso que, según José Luis Romero, fue común en Latinoamérica en este periodo, y se caracterizaba porque la población "apuraba su caída, abandonadas y en ruinas la mayoría de sus casas, y poblada solamente por viejos que arrastraban sus trabajos y sus días" (2005). Esa fue la realidad de numerosos poblados de la región entre los que se puede contar Petorca, expuesta a las vicisitudes de la economía regional que se manifiestan con meridiana claridad en el gráfico de población para la localidad durante el periodo 1813-1970 (ver Gráfico 1).

Hacia fines del siglo XIX Petorca representaba una ciudad que se había anquilosado, siendo su superficie urbana similar a la de 1780 , con aproximadamente un kilómetro de largo, por 300 metros de ancho. El cambio más importante que enfrentó fue la concesión del título de ciudad por decreto del

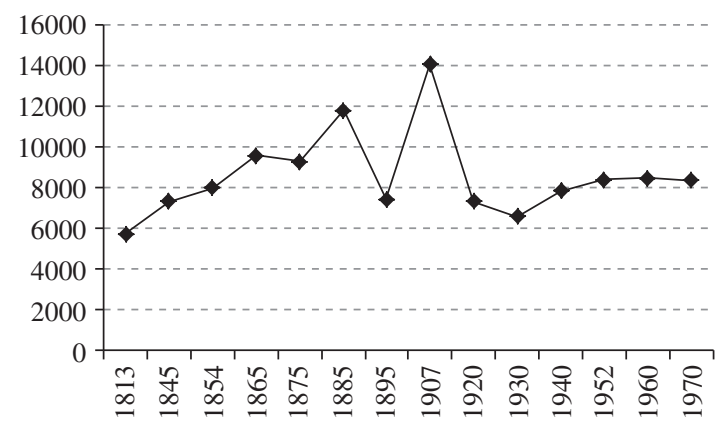

Gráfico 1. Habitantes de Petorca, 1813-1970.

Fuente: elaboración propia a base de información contenida en los censos de 1813, 1845, 1854, 1865; Oficina Central de Estadística 1875, 1885, 1895; Comisión Central del Censo 1907; Dirección General de Estadística 1920, 1930; Instituto Nacional de Estadística 1940, 1952.
23 de enero de 1870 (Astaburuaga, 1899), aunque este cambio cualitativo no se tradujo en nuevas construcciones o cambios, permaneciendo formada por calles irregulares, de tierra y cuyo principal atractivo era "una bonita plaza como paseo público" (Espinoza, 1895), donde la iglesia destacaba notoriamente en el paisaje urbano, como lo demuestra una fotografía tomada alrededor de 1900 por un ingeniero que destacó "el aspecto del pueblo es antiguo y la mayor parte de los edificios son bajos, de construcción de adobe y teja" (Fuenzalida, 1905), una imagen urbana que se proyectó hacia la primera mitad del siglo XX con escasas transformaciones.

\section{La(s) iglesia(s) de Petorca}

Hacia el inicio del siglo XX Lizana describió cada uno de los templos construidos durante el siglo XVIII, hasta el levantado por Pedro Luque Morenos en 1775. Esta información se complementa con las declaraciones del vecino Joseph Sepúlveda, proveniente del Paraguay, quien en un documento dirigido a la Capitanía General en 1781 afirmó que “cooperó con munificencia" (Lizana, 1910), manteniendo a su costa un largo pleito con los agustinos por los terrenos de la villa y financió "la fábrica de esta Santa Iglesia Parroquial de su primera piedra hasta su conclusión y adorno de cantidad de más de tres mil y quinientos pesos de mi caudal"12.

Si se atiende a lo afirmado por los pobladores la particularidad del caso de Petorca se debió a la iglesia edificada con antelación a la demarcación de la villa, un tema que el comisionado Antonio Martínez de Matta destacó:

\begin{abstract}
"Ha hecho en este vecindario en la construcción de esta santa iglesia parroquial en que ha gastado más de catorce mil pesos en su edificio y adorno correspondiente, como que no se haya ninguna semejante a esta en todas las construidas en las villas fundadas desde el año pasado de 36 lo que pedimos se sirvan vuestras mercedes de certificarlo como testigos oculares y todo resultado del sumo anhelo de este vecindario al culto divino deseoso de recibir el pasto espiritual para el alivio de nuestra alma"13.
\end{abstract}

Según el citado documento la construcción era de 51 por 9 varas y contaba con espesos muros con amarras de madera reforzada con "sólidos 
pilastrones". Resulta interesante destacar que la presencia de las torres era un elemento que caracterizó al poblado, como se aprecia en un plano levantado en 1796, destacando la iglesia como un hito urbano, siendo representada por una construcción dotada de una nave central y dos torres de gran altura (ver Figura 1) ${ }^{14}$. El citado Lizana destacó la solidez con que fue erigida esta iglesia, la que le permitió soportar los movimientos sísmicos de los años 1783 y 1789 .

\section{La iglesia decimonónica}

En las primeras décadas del siglo XIX Petorca enfrentó el terremoto de 1822, sufriendo severos daños en sus casas. A ojos del viajero Francis Bond Head, "las paredes de las casas estaban rajadas y hendidas de arriba abajo" y su iglesia "demolida" (Head, 1918). Es dable suponer que después de este sismo se inició una inmediata reconstrucción en manos del cura Juan Antonio, quien estuvo a cargo de la iglesia hasta 1829 (Gómez, 1970). La información existente acerca de la iglesia de Petorca en las décadas siguientes es escasa, solo

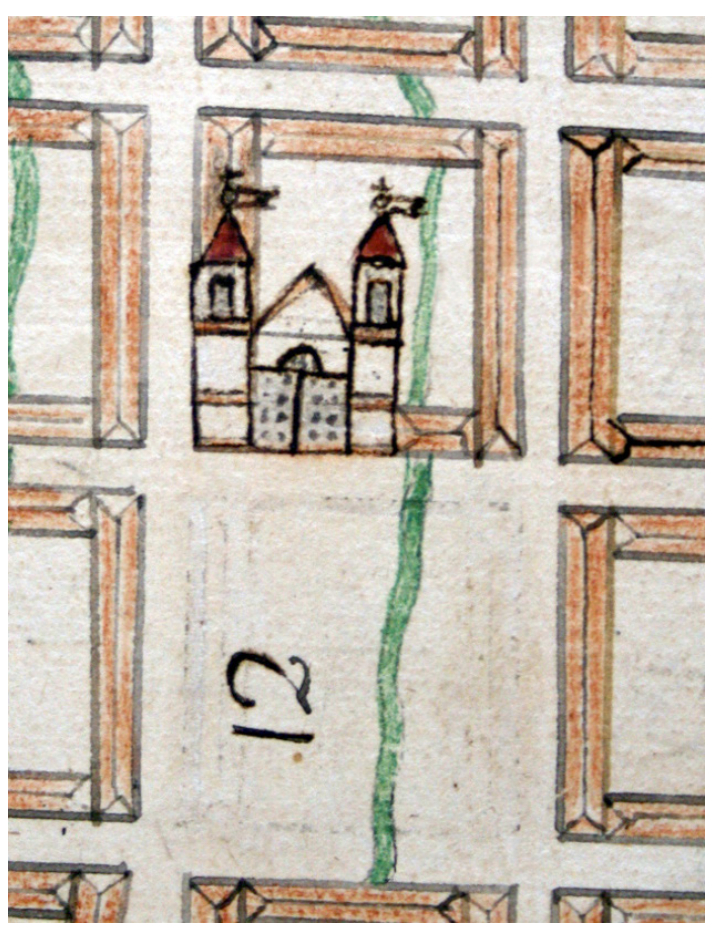

Figura 1. Detalle del plano de la Villa de Petorca y sus trapiches, 1796. Destaca la iglesia con sus dos torres, frente a la plaza mayor de la villa, representada con el número 12 . esporádicamente se hace referencia a su situación, aunque es de suponer que la iglesia hacia 1830 ya se había reconstruido, pues Ignacio Domeyko al recorrer la región al inicio de la década decimonónica de los treinta señalaba que la iglesia de la localidad era una de las más importantes de la región (Domeyko, 1978).

La iglesia sufrió, desde su construcción tardocolonial, profundas transformaciones debido a múltiples factores. Un balance de los cambios y daños ocasionados en el edificio, piezas de culto y bienes de la iglesia de Petorca - provocados por el tiempo, adversidades climáticas, terremotos y la persistente sustracción de piezas de culto- es posible avizorarse en las evaluaciones realizadas durante la confección de los inventarios parroquiales correspondientes al traspaso del cargo entre el cura saliente y el que se nombraba.

A mediados del siglo XIX la iglesia se encontraba a bastante mal traer y debe haber sido dañada de consideración en el terremoto del 8 de marzo de 1847, el que con epicentro en La Ligua y Petorca fue considerado "arruinador" (Taulis, 1930). No obstante, la descripción realizada en el inventario parroquial de 1854 por el cura José Delfín Iturrieta, corroborada por el de Ignacio Bacigalupo en 1865, destacaba que la iglesia se encontraba en buen estado ${ }^{15}$.

Aunque no existen mayores evidencias, los terremotos del 25 de marzo de 1871 y del 5 de julio de 1873 afectaron la región provocando, especialmente el último, los mayores daños en La Ligua y Petorca (Lanza, 2011), localidad donde según el ministro Altamirano en su memoria de 1874 informaba que se habían realizado algunas obras públicas en la plaza y jardines del poblado, destacando que la iglesia "está aún ruinosa" (Ministerio del Interior, 1874).

Basado en las fuentes mencionadas es posible constatar mantenciones (enladrillado, tejas, cambio de puertas, pintura externa) y cambios suscitados en la segunda mitad del siglo XIX. En efecto, en 1878 el cura Tristán Solís escribió que la iglesia "se ha reformado casi por completo"16, el coro se amplió en dos metros, se protegió con una nueva baranda, se entabló y pintó, realizándose además un conjunto de cambios en la iglesia, algunos de ellos, para el efecto de esta investigación, resultan muy gravitantes. Tal es el caso de las transformaciones hechas a la fachada de la iglesia, que más allá de presentar transformaciones estructurales, significó la aplicación de "adornos de madera blanca"17 sobre la pared. 
Aunque existen ejemplos anteriores, el inventario más acucioso y detallado fue elaborado por el cura Nemesio Rojas, quien al abandonar su cargo estableció que en la amplia propiedad se distribuía la iglesia y las construcciones formadas por tres cuerpos eran "de sistema antiguo y se halla en mal estado en su mayor parte" 18 , distribuidos en torno a un patio principal y tres patios secundarios, destinados a caballerizas, bodegas y dependencias de los curas. Uno de los patios estaba separado por doble tapial y fungía como campo santo.

La construcción contaba con tres secciones, estando la primera contigua a la iglesia y estaba formado por dos piezas de depósito, construidas con murallas de adobe, enmaderadas, con el piso enladrillado y techo de tejas. La siguiente sección consideraba tres piezas de diferente calidad donde destacaba la que poseía paredes empapeladas, cielo de género, piso enladrillado y sus paredes externas pintadas de plomo. El tercer cuerpo de edificios estaba formado por cuatro piezas que servían de comedor, sala de recibo, dormitorio y despensa, en estas la recepción se consideraba en "magnífico estado" y tenía enladrillado, géneros en el cielo, paredes empapeladas y puertas pintadas.

La iglesia correspondía a una construcción de 51 varas de largo por 81/4 de ancho y 7 de alto, tenía murallas dobles de adobe, con tres puertas antiguas con perillas de cobre, que enfrentaban la plaza y dos laterales, una hacia la calle Montt y la otra al interior de la iglesia. En el interior se encontraba enteramente empapelada y pintada de azul, enladrillada en el piso $\mathrm{y}$ tejada. El presbiterio, altar mayor y frisos interiores, arco coral, estaban pintados al óleo de color blanco. El coro cubría la parte superior de la pared oriente del edificio, estaba entablado y poseía una baranda, accediéndose a este mediante una escalera ubicada al lado sur que lo comunicaba con el primer nivel de la iglesia y la torre principal en que se ubicaban las campanas. En el nivel del coro existían dos puertas que permitían acceder a las torres.

La iglesia petorquina destacaba en la región por la presencia de sus dos torres ubicadas en el extremo oriente de las murallas laterales, cuyo frontis fue descrito a fines del siglo XIX por Elías Lizana, como coronado "por dos pequeñas torres, que semejaban almenas de fortaleza griega", cada una de ellas estaba compuesta por dos segmentos de diferente materialidad, calificadas en la época como en "mal estado", una contenía cinco campanas, permaneciendo solo una en uso. El texto de
Nemesio Rojas describió hacia 1880 las torres de la siguiente manera:

\begin{abstract}
"Ambas son exactamente iguales, de estilo antiguo, de mal gusto y se encuentran en mal estado. Constan de dos cuerpos, el primero de adobe, tiene por base una superficie de 13 metros cuadrados, por 9 [metros], 98 centímetros de altura. Esos cuerpos se encuentran en buen estado, aunque en la parte que empalman con las murallas laterales se han desprendido algún tanto de estas.

El segundo cuerpo es de madera y lo forma un cuadro imperfecto por sus dimensiones en sus cuatro lados. Este cuadro está sostenido por cuatro columnas que descansan en otras tantas basas de cal y ladrillo. Tanto esta como las columnas se encuentran destruidas en parte y exigen reparación. Además las caras de madera que forman cuadriláteros en las dos torres están también en mal estado, pues faltan algunas tablas que se han destruido por el tiempo y por

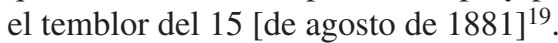

Este terremoto provocó daños en todos los edificios de la localidad y en particular de la iglesia, la que de acuerdo con un informe de Alberto Luco "al parecer se encuentra en mui mal estado"20. Desde ese momento las solicitudes de dinero para la reparación de la iglesia fueron permanentes.

El citado movimiento sísmico produjo la destrucción del tejado de la iglesia y el daño de 5 de los 15 estribos que defendían las murallas en el exterior y se encontraban separados de ellas y sus amarras dislocadas.

Un elemento importante en la estética del edificio era la fachada que daba a la plaza de la ciudad, formada por una portada de madera blanca pintada que consta de un medio punto en forma de triángulo, sostenido por cuatro columnas de orden corintio, las que descansan en basas de adobe, forradas en zinc para recibir las aguas lluvias. Las columnas con el temblor se aflojaron y estaban un tanto separadas del muro. A juicio del sacerdote, la fachada y el exterior sur de la iglesia, que daban a la calle, se encontraban "sumamente enlucidas, pero el exterior del lado norte que da a las casas parroquiales está blanqueado; pero el blanqueo se encuentra muy deteriorado" 21 . 
De esta manera la iglesia estuvo en permanente transformación, variando desde el diseño tardocolonial, que hacia inicios de la decimonónica década de los ochenta estaba bastante modificado.

\section{Un nuevo templo parroquial}

Después del terremoto del 15 de agosto de 1880 y debido a la deplorable situación en que quedó el edificio, se enfrentó la disyuntiva de reparar el templo existente o impulsar la construcción de uno nuevo. Dos años después del sismo y por orden del obispo Joaquín de Martiropolis, procedieron a la evaluación los ingenieros Ricardo Fernández y Miguel Olivares, quienes determinaron el ruinoso estado en que estaba la construcción y una pérdida de dinero la reparación, por lo que se determinó que era "indispensable pensar seriamente en la reconstrucción así de la iglesia como de la casa parroquial", ordenando al cura impulsar el levantamiento del plano "que en su concepto conviniera adoptar para la construcción del templo i que indicara el lugar en que pudiera construirse, el valor del trabajo y los recursos con que pudiera contarse" 22 , para llevar el proyecto a cabo.

Para el efecto, en el último bimestre de 1882 se encargó al arquitecto alemán Teodor Burchard Haberle, la confección de los planos de la nueva iglesia parroquial de Petorca, a base de los que se iniciaría la construcción del templo. Inmediatamente, el cura Alcides Vargas - partidario de construir un nuevo templo- procedió a elegir el sitio seleccionando el contiguo a la vieja iglesia, en que se ubicaban las derruidas casas parroquiales. El paso siguiente fue pedir autorización para poner la primera piedra, siendo aprobada el 21 de diciembre de 1882, obligando solo a "proceder a la bendición de la primera piedra usando para ello la fórmula que tiene el ritual romano" 23 .

Es probable que al fin de aquel año y comienzo de 1883 el arquitecto finalizara su tarea, debido a que el cura Alcides Vargas señaló en el inventario de este último año que la nueva iglesia parroquial ocuparía el lugar en que se encontraban las casas parroquiales -junto al emplazamiento de la iglesia actual- en una superficie edificada de aproximadamente 54 × 25 metros, señalando además que en "los trabajos se han seguido los planos de Teodor Burchard, cuyos planos [he] entregado a mi sucesor" ${ }^{24}$. Es interesante destacar el detallado informe que el cura hizo acerca de sus actividades en aras de erigir la nueva iglesia. Para el efecto, incluyó un acápite en el inventario, que denominó "nueva iglesia parroquial", donde estableció que:

\begin{abstract}
"se procedió a la construcción de una nueva iglesia parroquial, por estar la actual en estado ruinosa sin ser susceptible de una reparación por lo cual pudiese dársele a sus murallas solidez, siendo inútil todo gasto en este sentido según lo informado por los ingenieros [...]. Estos trabajos se iniciaron en el mes de diciembre del año pasado, en el lugar que ocupaban las casas parroquiales, las que fue necesario destruir, por estar en mal estado por su antigüedad y estragos causados en ella por los últimos temblores. Todas las zangas de los heridos están abiertas y ocupan una superficie de 36 varas de largo por 20 de ancho, y solo falta para trabajar los cimientos, el colocar la primera piedra, lo que no he hecho a pesar de estar autorizado para ello, por la circunstancia de estar por ausentarme definitivamente de la parroquia de día en día, hace tres meses. Sin embargo, el trabajo ha seguido pero con pausa y este ha consistido en las aglomeraciones de materiales, como ser el acarreo de piedras para los cimientos, la corta de adobes y ladrillos" 25 .
\end{abstract}

Queda bastante esclarecido que el plano elaborado por Burchard no fue llevado a la práctica. En esto influyó el grado de integración que existía entre los habitantes y lo que el edificio representaba, manifestándose en una actitud negativa frente al eventual derribamiento de la iglesia y sus torres. El texto de Elías Lizana permite sustentar con mayor solidez la inferencia anterior, debido a que hacia fines del siglo XIX un sacerdote, posiblemente Moisés Lara, quien detentaba esa condición en $1886^{26}$, "había pensado en sustituir el vetusto templo por una iglesia de construcción moderna, su idea que no fue bien aceptada por la feligresía de principal representación y hubo de desistir de ella" (Lizana, 1910). A partir de allí se puede establecer que los pobladores veían en su templo parte de su pasado y le asociaban al lugar en que se juró la independencia, donde se bautizó a José Manuel Borgoño y Manuel Montt y "muchos troncos" de familias de la elite regional del país. Allí también se habían 
celebrado los triunfos sobre España, en 1865 y los correspondientes a la Guerra del Pacífico ${ }^{27}$. En síntesis, si atendemos a las palabras de Lizana, la iglesia se imbricaba con la historia de la localidad, hecho que hacía imposible generar un cambio de esas características.

Por otra parte, también queda claro que la "construcción moderna" a que refiere el texto estaba basada en los planos de Burchard, ya que las fuentes no indican otra inversión en un diseño alternativo. Es dable pensar lo anterior a base de que el costo del plano elaborado por Burchard tuvo un costo de $\$ 2.000$, una suma no escasa para la época ${ }^{28}$. El tema se esclarece al observar que según la correspondencia con las autoridades del nivel central, el templo estaba permanentemente "en construcción", afirmación sobre la que se insiste en julio de 1883, pese a que los únicos planos existentes estaban extraviados en Santiago ${ }^{29}$.

Frente a la riqueza de la información contenida en los documentos citados es posible establecer que, más que una reconstrucción total, la iglesia recibió sucesivas y parciales transformaciones. Esto, pese a que el gobernador Luco solicitó recurrentemente en el mismo periodo se erigiera una nueva. Efectivamente, entre 1882 y 1883 se destinaron desde el gobierno central aproximadamente $\$ 3.400$ para ejecutar reparaciones ${ }^{30}$. Las asignaciones parciales persisten, aunque en total no llegan a una suma de importancia, como la que demandaría un nuevo edificio.

Es importante destacar que las torres construidas a fines del siglo XVIII y reconstruidas después del terremoto 1822 persistían aun en 1897 (Lizana, 1910), las que "como homenaje vituperioso y sarcástico del siglo XX, en uno de sus primeros años fueron demolidas" (Lizana, 1910). La afirmación realizada por el cura local es congruente con la evidencia fotográfica que existe para el periodo, la que muestra una construcción de una sola torre (ver Figura 2). La fotografía en cuestión fue hecha antes de 1904, debido a que el libro se editó al año

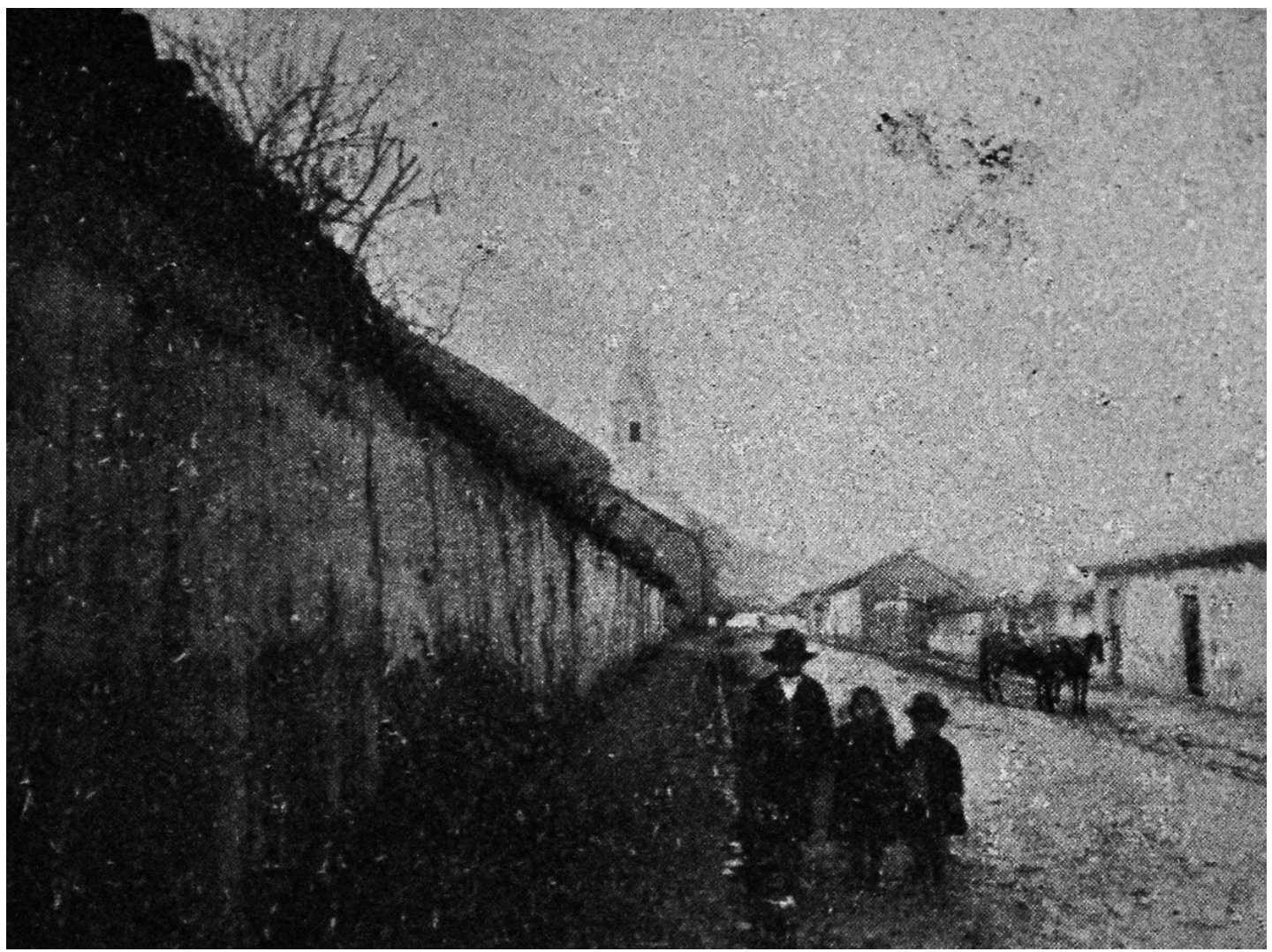

Figura 2. Calle del Molino, actual calle Manuel Montt. Petorca, circa, 1904. Obsérvese al fondo la iglesia con una sola torre. 
siguiente, por ende el derribamiento de las torres acaeció entre 1901 y 1904.

Las sumas parciales para reparaciones persisten durante el siglo XX: en 1904 el gobierno aportó $\$ 1.500^{31}$ y $\$ 3.000$ en marzo de 1906 . Como destacaba con antelación, a la sazón, la iglesia ya contaba con una sola torre y las opiniones tendían a cambiar al inicio del siglo XX, según Lizana "era el sueño dorado de algunos petorquinos ver reemplazada esa venerada antigüedad por una iglesia de tres naves, como las que poseen las principales ciudades, y como las encontramos también en algunas apartadas aldeas" (Lizana, 1910).

El terremoto que se desencadenó el 16 de agosto de 1906, cuando los relojes marcaban las 19:55 horas, rompió abruptamente la tranquilidad del poblado y dejó la iglesia en peores condiciones: se derribó su torre recientemente construida y causó importantes daños sobre las murallas de la iglesia, la que finalmente enfrentó la demolición de las murallas de adobe hacia la primera década del siglo XX. Comisionado por el gobierno, el sismólogo francés Fernand Montessus de Ballore realizó un importante informe de la situación en la región, encargando la iglesia de Petorca al funcionario de Obras Públicas J. Holscheuer, quien evaluó el edificio estableciendo la desmedrada situación en que quedó:

\begin{abstract}
"toda la techumbre de la nave única, desde el arco del presbiterio, se ha caído, destrozando parte de los altares que no tienen más mérito que su gran antigüedad. Las murallas laterales se mantienen perfectamente a plomo. Daños de importancia en la sacristía y en el presbiterio. Los desperfectos sufridos por el cuerpo del edificio en que descansa la torre son debidos a que las murallas no eran marradas en cuadro con las soleras-llaves. Esta iglesia debe hacerse completamente de nuevo, dada la importancia de los desperfectos" (Montessus de Ballore, 1914).
\end{abstract}

Este hecho requiere de algunas preguntas acerca del nivel de destrucción y la construcción inmediata de un nuevo templo, principalmente porque las asignaciones monetarias solicitadas para resarcir los daños del terremoto alcanzaban en primera instancia $\$ 5.000$ para la iglesia de Petorca y de $\$ 15.000$ para la de Hierro Viejo ${ }^{32}$, dinero que finalmente se aumentó para Petorca fijándose en \$10.000.
Una lectura apresurada de las escasas fuentes existentes para elucidar este tema puede inducir a pensar que inmediatamente después del terremoto se construyó una nueva iglesia, hecho que no se condice con las nuevas asignaciones por un monto de $\$ 4.000$ y $\$ 1.200$, aprobados respectivamente el 8 y 22 de abril de 1907, que sumarían $\$ 15.200$, una cantidad que solo permitía reparaciones.

De estos datos se puede deducir que el aporte fue, contradictoriamente, más importante para Hierro Viejo, un poblado menor y con una feligresía numéricamente exigua, comparada con Petorca. Además, si se analizan los daños del terremoto de 1906 en La Ligua, cuya iglesia resultó completamente destruida, se puede observar que su reconstrucción, si se considera el plano del edificio proyectado con sus tres naves, similar en tamaño al de Petorca, tenía un costo que ascendía a alrededor de $\$ 50.000$, de cuya cifra el gobierno cubriría el 50\%, considerando una construcción hecha en fierro y cemento armado ${ }^{33}$ en sus murallas.

Entonces, la evidencia hace suponer que la construcción de la iglesia después del terremoto de 1906 fue paulatina y se realizó en el largo plazo, acorde con la realidad constructiva de los templos de la región. La información más clara, que corrobora lo afirmado, es refrendada por las investigaciones hechas en el lugar por Alfredo Benavides, quien afirmó que en 1906 "se vino al suelo la iglesia". A partir de este último punto es dable destacar que Benavides era un arquitecto de vasta experiencia y estaba realizando en la década de los treinta una investigación que tenía como tema central la arquitectura colonial chilena y peruana. No obstante, en su libro no hace alusión alguna al edificio mismo, destacando solo la destrucción del rico patrimonio e imaginería religiosa, altares y retablos realizados por José Santos Niño y Figueroa, conocido como el "Tallador de Petorca". Entonces ¿debemos interpretar ese silencio como una omisión del arquitecto? Pareciera que no, ya que este autor destaca que la situación de carencia de templo se revirtió en 1910, cuando el cura Manuel de Jesús Fariña "había levantado con gran esfuerzo y muy pocos recursos el templo parroquial" (Benavides [1941], 1988).

\section{La tradición de una invención}

En síntesis, a partir de la evidencia historiográfica detectada en nuevos documentos ubicados en el Archivo Parroquial es posible establecer una 
serie de premisas respecto de la historia de la iglesia de Petorca:

A) En términos de su estructura inicial, el templo fue levantado por Pedro Luque Moreno en 1775 y permaneció relativamente similar hasta el terremoto de 1822, cuando debió ser reconstruido.

B) Desde 1854 en adelante las fuentes historiográficas evidencian un notable deterioro del edificio, el que fue sometido a reiteradas intervenciones superficiales y con carácter de mantención.

C) En 1878 se realizaron intervenciones de importancia al interior de la iglesia, especialmente en el "ensanchado" del coro, mas ninguna de ellas fue de carácter estructural.

D) El terremoto de 1880 causó graves daños a la iglesia, poniéndola en peligro de derrumbe.

E) Los daños citados provocaron una larga discusión entre la comunidad petorquina dividiéndola entre los partidarios de la reparación y quienes proponían la sustitución por un nuevo templo.

F) En 1882, la jerarquía eclesiástica nacional se inclinó por construir un nuevo templo, cuyo plano fue encargado al arquitecto alemán Theodor Burchard, quien finalizó su trabajo en los primeros meses de 1883 .

G) La iglesia diseñada por Burchard era un rectángulo de 36 por 20 varas, cuyos "heridos" se iniciaron en abril de 1883 contiguo al actual templo, por el lado norte, donde se ubicaban las casas parroquiales que fueron destruidas debido a los daños del terremoto. Este trabajo careció de financiamiento por parte del gobierno, por ende, la construcción de la iglesia no se concretó.

H) Los montos aportados por el gobierno central se limitaron a remesas de dinero paliativas, para reparar los daños más urgentes y necesarios. Producto de esto entre 1901 y 1904 las dos torres que caracterizaron a la iglesia colonial fueron derrumbadas debido al peligro que representaban.

I) Entre 1904 y 1906 la iglesia transitó desde la carencia de sus torres a la construcción de una sola, la que fue nuevamente derribada por el terremoto del 16 de agosto de 1906 y provocó daños estructurales en la antigua construcción.

J) Finalmente, fue el terremoto de 1906 el que obligó a proyectar la construcción de una nueva iglesia, que significó un largo proceso, probablemente, no menor a una década.
Aunque no existen evidencias documentales para el caso de Petorca, esta afirmación es posible de realizar a partir de la comparación con los procesos seguidos por las iglesias de las ciudades aledañas, V. Gr, en La Ligua.

Como corolario de lo expuesto, y frente a la evidencia documental presentada, resulta curiosa la contradicción evidente entre el año 1857 fijado en la declaración de Monumento Nacional del 2009 y la insistencia por parte del Ministerio de Obras Públicas en que este inmueble "tuvo varias reconstrucciones producto de numerosos sismos que afectaron su estructura. El edificio actual fue diseñado por Teodoro Burchard en 1882, con estructura de madera y adobe"34. Sabido es que el diseño de Burchard solo quedó a nivel de sus bases y que el plano que realizó en 1883 finalmente resultó perdido.

Solo cabe preguntarse acerca de los móviles que orientan estos procesos de declaración de monumentos nacionales. Un primer elemento que explica estas prácticas es el mercado turístico resultante del auge del consumo que convierte la-cultura-en un bien transable que inserta la patrimonialización en la lógica de la globalización, sobrepasando los móviles del Estado-Nación. En segundo lugar, aparece como explicativo el reforzamiento de la memoria colectiva de la comunidad, que más allá de pretender la restauración de elementos patrimoniales de antigüedad y valor incuestionables, son parte de una postura epistemológica que busca "recrear" elementos perdidos en los espacios urbanos. Probablemente, esta es la respuesta al devenir de un mundo tecnologizado, producto del cual-como escribió Antonio Ariño- "nos invade la nostalgia por los tiempos y espacios perdidos, una añoranza romántica por imágenes, sabores, sensaciones, recuerdos, que la lluvia de la modernidad avanzada arrastra inmisericordiosamente hacia el mar del olvido" (Ariño, 2002).

De otra manera, es difícil comprender ciertas prácticas que estimulan el uso de viejas tejas en edificios nuevos, generando unos ambientes urbanos dignos de escenificaciones de Hollywood -a la manera de la arquitectura reciente en La Serena- o la homogeneización cromática de azules, rojos y amarillos "coloniales" que invaden antiguas ciudades latinoamericanas para darle "sabor a pasado" a los frontis, como parte de una política donde prima, más que la protección de los escasos elementos patrimoniales existentes, la generación de espacios 
urbanos resultantes en verdaderas locaciones fílmicas que transportan al habitante a un pasado citadino sepia, en que se provoca una intencionada alteración engañosa del paisaje urbano y del espacio donde -en el decir de Karl Schlögel- "leemos el tiempo" (Schlögel, 2007).

En la dimensión monetaria del tema esto contribuye de manera importante a aumentar la llegada de los anhelados turistas que dinamizan las economías locales en sus tournée turísticas ávidas de pasado. Para el caso de Petorca y su iglesia es dable pensar que sucede algo similar a lo acontecido en otras regiones de Latinoamérica, donde se ha constatado que las tradiciones "representan una oportunidad innegable de mercado y accionar político, sobre todo para los pequeños gobierno locales" (Chara, 2012).

Así, a inicios del siglo XXI una particular versión de la historiografía parece ser la comparsa presente en todos los actos o emprendimientos "culturales" a nivel local. Mientras que en la dimensión de la industria cultural se han "empaquetado tantos productos con la etiqueta de la historia" que ha redundado en una devaluación de lo que se comprende como "histórico" (Aravena y Sobarzo, 2010).

Pareciera que en aras de la patrimonialización la historiografía y su análisis de la veracidad -que busca inscribirse "en el orden de un saber universalmente aceptable, científico, en el sentido de Michel de Certau" (Chartier, 2007)- pasa a ser un instrumento utilizable solo cuando permite corroborar antigüedades de un tiempo remoto $u$ otorgar los galardones que lo confieran, aunque esto implique interpretar (a veces) gratuitamente los datos y actores de ese pasado.

\section{Agradecimientos}

Mis agradecimientos a Pablo Aravena, Leopoldo Benavides, Pilar González, Nicolás Richards, Manuel Fernández y Marco Murúa, quienes contribuyeron con comentarios y aportes a este trabajo, aunque la responsabilidad final me pertenece.

\section{Referencias Citadas}

\section{Anónimo}

1995 El Romance de los siete ladrones, en Milton Godoy Orellana, "Documentos para el estudio de la historia regional". Valles. Revista de Estudios Regionales. 1, Centro de Estudios Regionales del Patrimonio Cultural, $\mathrm{N}^{\circ} 1: 99$

Aravena, Pablo y Mario Sobarzo

2010 Valparaíso: patrimonio, mercado y gobierno, Ed. Escaparate, Concepción, 2010.

Aravena Núñez, Pablo

2014 La "memoria" patrimonial como obstáculo epistemológico, de la operación histórica.

Ariño, Antonio

"La patrimonialización de la cultura y sus paradojas en la sociedad del riesgo”, en J. M. García y P. Navarro ¿Más allá de la modernidad? Las dimensiones de la información, la comunicación y sus nuevas tecnologías, Madrid, pp. 329-352.

Astaburuaga Francisco

1899 Diccionario geográfico de Chile, Imp. de P.A. Brockhaus, Leipzig, p. 660.

Barros Arana, Diego

1884 Historia de Chile, T. I, Ed. Jover, Santiago.

Barros Arana, Diego

2000 Historia General de Chile, Vol. 6. Ed., Universitaria, Santiago.

Benavides Rodríguez, Alfredo

1941 Arquitectura del virreinato del Perú y de la Capitanía General de Chile, Ed. Universitaria, Santiago, 1988, pp. 242-243.
Bonfil Batalla, Guillermo

1991 Pensar nuestra cultura, Alianza, México. 2005 "Qué pertenece a quién: Procesos de patrimonialización y Pueblos Originarios en Patagonia", Cuadernos de Antropología Social $\mathrm{N}^{\mathrm{o}} 21: 133-149$.

Censo de 1813.

1953 Levantado por Don Juan Egaña, de orden de la Junta de Gobierno formada por los Señores Pérez, Infante y Eyzaguirre. Santiago: Imp. Chile, p. 93.

Chara, Alberto

2012 "La re-invención de la tradición Inka y su comercialización turística". Turismo y Sostenibilidad, V Jornadas de Investigación en Turismo, Edición Digital Tres, España, p. 693.

Choay, Françoise

2007 Alegoría del patrimonio, Ed. Gustavo Gili, Barcelona, Barcelona.

Dirección de Arquitectura Ministerio de Arquitectura, V Región 2010 "Restauración y puesta en valor iglesia nuestra señora de La Merced de Petorca", abril. CEDOC, Carpeta 59.1, s/f

Domeyko, Ignacio

1978 Mis viajes. Memorias de un exiliado, Santiago, Editorial Universidad de Chile, p. 480.

Espinoza, Enrique

1895 Geografía descriptiva de la república de Chile, Santiago, Imp. Barcelona, p. 162.

Fuenzalida, José del C.

1905 Monografía minera de la provincia de Aconcagua, Imp. Universo, Santiago, p. 156. 
Godoy, Milton

2007 Chinos. Mineros danzantes del Norte Chico chileno, siglos XIX y XX, Ed. Universidad Academia de Humanismo Cristiano.

Gómez, Avelino

1970 Viajeros pontificios al Río de La Plata y Chile (18231825): la primera misión pontificia a Hispano-América relatada por sus protagonistas, Vol. 1, Ed. Gobierno de Córdoba, Córdoba, Buenos Aires, p. 141.

Guarda, Gabriel

1978 Historia urbana del Reino de Chile, Ed. Andrés Bello, Santiago. Q

Head, Francis Bond

1918 [1826] Las pampas y los Andes. Notas de viaje, Imp. de La nación, Buenos Aires, p. 179.

Hernández, Manuel, Milagros Aguirre, Chantal Naudon, Luis Castro. 2008 Expediente técnico declaratoria de monumento histórico iglesia nuestra señora de La Merced de Petorca, Centro de Estudios y gestión del patrimonio, Universidad de Valparaíso.

Hobsbawm, Eric y Terence Ranger.

2002 La invención de la tradición, Ed. Crítica, Barcelona.

La voz de Aconcagua. San Felipe, 25 de febrero de 1909.

Lanza, Carlos

2012 Catástrofes de Chile: álbum de prensa de antaño, Ed. RIL, Santiago.

Ley $\mathrm{N}^{\circ}$ 17.288 De los Monumentos Históricos Título III, Artículo $9^{\circ}$. Santiago, Diario Oficial, 4 de febrero de 1970.

Lizana, Elías

1910 "Apuntes para la historia de Petorca". Revista Católica,

T. XIX, Año 9, Nº 200, 20 de noviembre. Ed. San José, Santiago, Pp. 607-612.

Llorenç Prats

2005 "Concepto y gestión del patrimonio local", Cuadernos de antropología social, $\mathrm{N}^{\circ}$ 21, Buenos Aires, pp. 18-20.

Lorenzo, Santiago

1986 Origen de las ciudades chilenas. Las fundaciones del siglo XVIII, Ed. Andrés Bello, Santiago.

Lorenzo, Santiago

2004 Fuentes para la historia urbana del reino de Chile, 2: Régimen legal de la fundación de ciudades en Chile durante el siglo XVIII, Ed. Academia chilena de la historia, Santiago.

Lorenzo, Santiago y Rodolfo Urbina

1978 La fundación de ciudades chilenas durante el siglo XVIII. Ed. El Observador. Quillota.

McCaa, Robert

1983 Marriage and fertility in Chile: demographic turning points in the Petorca Valley, 1840-1976, Colorado, Westview Press, p. 26.

Memoria del Interior presentada al Congreso Nacional 1874 Imp. Nacional, Santiago, p. 371.

Montessus de Ballore, Fernand

1914 "Historia sísmica de los Andes Meridionales al sur del paralelo XVI", Annales de la Universidad de Chile, Santiago, 1914, p. 179.

Morel, Carlos

2008 "Políticas oficiales y patrimonialización en el carnaval porteño", Runa, No 28 , pp. 139-156;

Ortega, Luis

2005 Chile en ruta al capitalismo. Cambio, euforia y depresión, Ed. DIBAM, Santiago.

Romero, José Luis

2005 Latinoamérica, las ciudades y las ideas. Ed Siglo. Buenos Aires. p. 324.

Schlögel, Karl

2007 En el espacio leemos el tiempo. Sobre historia de la civilización y geopolítica. Ed. Siruela, Madrid, pp. 265-269.

\section{Archivos y fuentes primarias}

Archivo CEDOC, Solicitud N 629, Carpeta 59.1.

Archivo Nacional Histórico de Chile, Fondo Capitanía General: Vol. 490, Vol. 1031.

Archivo Nacional Histórico de Chile, Fondo General: Vol. 18.

Archivo Nacional Histórico, Fondo Mapoteca: Vol. 230.

Archivo Nacional. Histórico, Intendencia de Aconcagua: Vol. 143, Vol. 154.

Archivo Parroquial de Petorca: Inventarios de la parroquia años 1864, 1878, 1881, 1883.

\section{Notas}

1 Para el efecto ver Ministerio de Obras Públicas Dirección de Arquitectura, V Región, "Restauración y puesta en valor iglesia nuestra señora de La Merced de Petorca”, abril 2010. CEDOC, Carpeta 59.1, s/f.

2 Ley N ${ }^{\circ}$ 17.288. De los Monumentos Históricos Título III, Artículo $9^{\circ}$. Santiago, Diario Oficial, 4 de febrero de 1970.

3 Decreto declaración de monumento nacional Iglesia de Nuestra señora de la Merced de Petorca. Santiago, 27 de enero de 2009. Archivo CEDOC, Solicitud No 629.

4 Anónimo, El Romance de los siete ladrones [1779], en Godoy, 1995:99.

5 Entre estas se contaba además Huasco, Illapel, Sotaquí, La Ligua, Perquilauquén, La Estrella, Las Salinas, San Francisco del Monte, Chimbarongo, El Tambo de Colina, la Isla Maule. Para el tratamiento de este tema ver Barros Arana, 2000; Guarda, 1978; Lorenzo y Urbina, 1978; Lorenzo, 1986; Lorenzo, 2004.

6 Estas fundaciones se materializaron con la visita de Ambrosio O’Higgins al norte de la Capitanía General, refundando
Illapel, Petorca y La Ligua. Los principales documentos de estos juicios están contenidos en el Archivo Nacional Histórico de Chile, Fondo Capitanía General (en adelante ANHCG), Vol. 490 y Archivo Nacional Histórico de Chile, Fondo Varios (en adelante ANHFV) Vol. 18, respectivamente.

7 Los vecinos pobladores de la villa de Santa Ana de Briviesca en la provincia de Chile con el Padre Procurador de Combento de los Agustinos de dha ciudad de Chile. Madrid, 9 de enero de 1761. Pza $1^{\text {a }}$, fs. 3.

8 Autos sobre la fundación de Petorca. Petorca, 17 de marzo de 1780. ANHFV, Vol. 18, fs. 1.

$9 \quad$ Ibíd. Fs. 3.

10 Autos sobre la fundación de La Ligua (ANHCG), Vol. 490, fs. $134 \mathrm{~V}$.

11 Ver Plano de la villa de Petorca y sus trapiches. Archivo Nacional Histórico, Fondo Mapoteca, 1796.

12 ANHCG, Vol. 1031, Fs. 178.

13 Autos sobre la fundación de Petorca. Petorca, 17 de marzo de 1780. ANHFV, Vol. 18, fs. 33V. 
14 Plano de la villa de Petorca y sus trapiches, 1796, AHNCG, Volumen 230.

15 Ignacio Bacy - Galup, Inventario de la parroquia de Petorca año de 1864. Archivo Parroquial de Petorca (en adelante APP), Petorca 11 de octubre de 1864. Pág. 3-4.

16 Tristán Solís, Inventario de la parroquia de Petorca, año de 1878. Petorca, 26 de marzo de 1878. APP, s/vol. Pág. 5.

17 Ibíd., 9-10.

18 Nemesio Rojas, Inventario de la parroquia de Petorca, año de 1881. Petorca, 2 de septiembre de 1881. APP, s/ vol. Pág. 1.

19 Nemesio Rojas, Inventario... APP 46-47.

20 Archivo Nacional. Histórico, Intendencia de Aconcagua (en adelante ANHIA). Petorca, 25 de agosto de 1880 Vol. 143, fs. 239.

21 Ibídem. 49.

22 Carta del obispo Joaquín de Martiropolus. Santiago, 30 de octubre de 1882. APP. Documento $\mathrm{N}^{\circ} 15$, papeles sueltos.
23 Carta del Vicario Capitula autorizando postura de primera piedra. Santiago, 21 de diciembre de 1882. APP. Papeles sueltos.

24 Alcides Aurelio Vargas, Inventario de la parroquia de Petorca, año de 1883. Petorca, 8 de abril de 1883. APP, s/ vol. Pág. 22.

25 Alcides Aurelio Vargas, Inventario de la parroquia de Petorca, año de 1883... APP, 21-22.

26 ANHIA. Petorca, 1 de marzo de 1886 Vol. 154, fs. 85.

27 Ibíd.

28 Libro de Fábrica de la Iglesia parroquial de Petorca. APP, Petorca, 8 de abril de 1883 .

29 Petorca, 17 de julio de 1883. ANHIA, Vol. 143, fs. 273.

30 Libro de Fábrica de la Iglesia parroquial de Petorca. Petorca, 2 de agosto de 1883. Libro $N^{\circ} 9$, fs. 2-4.

31 ANHIA. Santiago, 20 de abril de 1904. Vol. 230, fs. 810.

32 ANHIA. Santiago, 31 de octubre de 1906. Vol. 290, foja 372.

33 La voz de Aconcagua. San Felipe, 25 de febrero de 1909.

34 http://arquitectura.mop.cl/centrodocumental/Documents/ arqmop_mayo\%202011_02.pdf. La cursiva es mía. 